\title{
The Seismic Sedimentology Application Research on Junggar Basin
}

\section{Chuanchun Song, Shuhua Wang, Yulei Qiao, Chen Lin}

Western Branch, Research Institute of Exploration \& Development, Shengli Oilfield Company, Sinopec, Dongying City, China

Email: 15254467998@126.com

How to cite this paper: Song, C.C., Wang, S.H., Qiao, Y.L. and Lin, C. (2016) The Seismic Sedimentology Application Research on Junggar Basin. Open Journal of Yangtze Oil and Gas, 1, 27-45. http://dx.doi.org/10.4236/ojogas.2016.12006

Received: May 6, 2016

Accepted: July 28, 2016

Published: July 31, 2016

Copyright $\odot 2016$ by authors and Scientific Research Publishing Inc. This work is licensed under the Creative Commons Attribution International License (CC BY 4.0)

http://creativecommons.org/licenses/by/4.0/

\begin{abstract}
Depending on different seismic frequencies and reflection interface information of sedimentary bodies, the core technologies involved in sedimentology had been introduced into clastic transpressional basins developing in Junggar Basin in the ways of the macro (seismic geomorphology) and micro (seismic lithology) to design a data interpretation process in double domain (time domain and Wheeler domain) in minimum isochronal strata unit. The isochronal horizon slice technique suitable for a variety of sedimentary models had been improved. The combination calibration and conversion of drilling data and seismic data were first realized according to unchangeable double domains time and depth relationship. A set of reservoir description technique was preliminary formed to be applied to lithologic identification, palaeosedimentary environment recovery, reservoir evolution and favorable reservoirs description basing on the analysis of stratigraphic sedimentary rhythm, which had been applied to the center of Junggar Basin and confirmed to be a worthwhile technique depending on seismic sedimentology for accurate reservoir description.
\end{abstract}

\section{Keywords}

Seismic Sedimentology, Wheeler Conversion, Double Domains Interpretation, Stratigraphicisochronal Slice, Junggar Basin Clastics

\section{Introduction}

The seismic sedimentology is a new subject which is being developed on seismic stratigraphy and sequence stratigraphy based on modern sedimentology and geophysics theories. It is used to study sedimentary physical attributes, shape distribution and evolution by sequence stratigraphy, stratigraphic sections, seismic attribute analysis and geomorphology [1] [2] [3] [4].

It is recognized that the frequency of seismic data controls seismic reflection dips and 
internal reflection configuration by seismic imaging. The seismic events is neither a simple isochronal reflection nor a simply lithology reflection, it is controlled by seismic frequency. The different frequency of seismic data reflects different geological information. The low frequency information reflects more lithology interfaces and high-frequency reflects more isochronal sediment interface information [1] [2] [3] [5] [6]. This breakthrough discovery has improved the connotation and extension of seismic stratigraphy, and provided a theoretical foundation of seismic sedimentology development and support for the identification and descriptions of subtle reservoirs. Based on this understanding, in order to improve seismic recognition accuracy for thin layer, the innovative raised surface-line-point of unconventional research ideas was developed to overcome the past point-line-surface way of thinking and improve thin lay identification accuracy by continuous stratum imaging and high-resolution horizontal characteristics [4].

Seismic sedimentology theoretical basis, the core ideas, research content and ideas are more unified understanding after more than ten years of development. But its concept connotation and extension, especially in the key methods and techniques there are some controversies. Domestic study of seismic sedimentology is still focused on the conceptual analysis, in general, practical applications are more the concept and initial applications in published articles were mainly discussed. The key technology research methods were less [7]-[16]. Continental basin sedimentary changed rapidly in vertical with a narrow sedimentary facies in horizontal, as a result there is multi-solution in seismic sedimentology [17] [18] [19], and results in the limitation of further application in practice. There are still many limitations for the core technology of current seismic sedimentology ( $90^{\circ}$ phase shift, formation slices) application to Junggar Basin. Therefore, there are both theoretical forward-looking and challenging for carrying out seismic sedimentology, also are practical exploration needs.

\section{Regional Geologic Background}

Junggar Basin was a large transpressional clastic sedimentary basin at Mesozoic Jurassic. At late Middle Jurassic, the Yanshan tectonic was characterized by twisting effect, a series of NE, NNE of the thrust fault had been formed along the twisting surface or sub-structure shear plane, but a series of positive and negative tectonic units had also been formed. Prospective study area is located in the central region in the Middle Basin (Figure 1). From north to south it is across the central depression, central uplift and the Tianshan piedmont depression, it is slightly rectangular extension from west to east, which is facing Northern Tianshan piedmont thrust fault-fold belt, and southern Luliang Uplift, and it is also locating between Baijiahai Uplift and Zhongguai-Badasong Uplift. The Basin is consisted of Pen1 Sag, north Dongdaohaizi Sag, Changji Sag and two uplifts of Mobei and Maqiao. There is a large south-dipping tectonic background in central Basin with deep depth and low exploration. The fault was not developed in the area with simple structure and no obvious large positive structure. There are three segments developing at Sangonghe Formation in Jurassic, and the second segment is a 


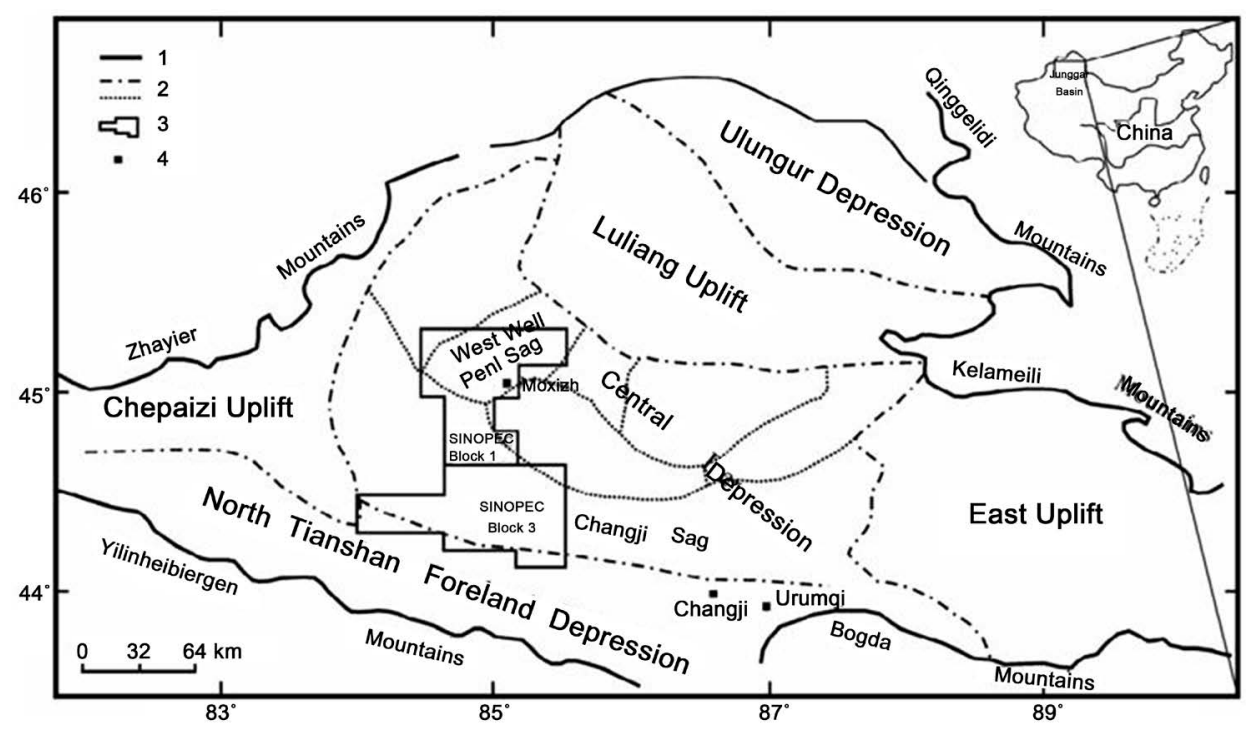

Figure 1. Tectonic setting of the Junggar Basin and the location of the study area (1. Basin boundary; 2. tectonic boundary; 3. SINOPEC Block boundary; 4. Location).

major exploration formation and there are two positive rhythm sandy beds of $\mathrm{J}_{1} \mathrm{~s}_{2}{ }^{2}$ and $\mathrm{J}_{1} \mathrm{~s}_{2}{ }^{1}$ developing from down to up.

\section{Adaptability Analysis}

The seismic sedimentary technology, which was derived from marine sedimentary basin study, was introduced into the study of continental basin to result in multiple resolutions due to its different adaptable conditions. So it is limited to be applied further to continental sedimentary basins, many scholars have not appraised of seismic sedimentology. The key technologies can be constrained or extended according to seismic sedimentology connotation. The 90 degree phase shift technique is mainly to achieve converting the interface responses reflected by thin layers with wavelength less than a quarter into body responses through the phase transition. The peak or trough was corresponded to the middle of thin layer in order to describe conveniently and identify reservoirs. The clastics depositing in continental transpressional basin change rapidly in lateral, which can be identified by constrain inversion instead of 90 degrees phase shift guiding on seismic sedimentology. For the formation slicing, slice model can be extended to build new isochronal stratigraphic slices.

\subsection{Study Content}

The core of the seismic sedimentology is to use seismic (response) characteristics to study the deposition body. Its formation depends on the sedimentary environment (facies). So the key issues of the seismic sedimentology have two, one is the deposition response characteristics (seismic lithology) of seismic body, and the second is apalaeogeographical environment (sedimentary environment) recovery (seismic geomorphology), among which seismic lithology is to build the relationship creating from lithology 
and physical parameters and seismic velocity and density through studying the impact resulted from lithology, porosity and pore fluid on elastic properties of rocks under the condition of different temperature and pressure. Seismic geomorphology is to characterize seismic phases using variable seismic attributes within an isochronal unit in the way of planar slice to analyze reservoir property and its evolution. Therefore, the seismic sedimentology is adaptable for continental transpressional basins for its content of the study.

\subsection{Key Techniques}

\subsubsection{A Lithology Predict Technique}

The Logging constrained seismic inversion technique is to use high frequency information and complete low frequency abstract from logging data to complement the limited bandwidth of seismic data, and calculate high resolution stratigraphic lithologic constrained by geologic information and logging data to provide a reliable basis for describing accurately reservoir depth, thickness, material.

1) It is not to predict accurately reservoir lithologiconly using wave impedance due to reservoir and non-reservoir overlapping frequently. So it can first build reservoir characteristic curves basing on reservoir lithology, electrical, and material responses to carry out reservoir features inversion.

2) For the thin reservoir sand body characteristics, frequency division could be used to inversion. Firstly the frequency bandwidth of the seismic data was analyzed to design an appropriate scale for frequency division. The amplitude and frequency relationship (AVF) could be calculated for different thickness bodies after data frequencies were divided and the AVF was introduced into inversion to build nonlinear mapping relationships between logging wave impedance curves and seismic waveform to combine the synthetic inversion cube.

\subsubsection{An Isochronal Stratigraphic Slice Technique}

There are three conventional stratigraphic slice technologies. One is time slice which is suit for relatively flat formation due to impact of stratigraphic dip. Second is to find a isochronal interface above the target stratigraphic or below stratigraphic to flaten it, and then slice the flatened data to regard as an approximate relative age cube, which is suit for more stable sedimentary environment and the top and bottom of stratigraphic are relatively parallel. Third is stratigraphic slice to flatenseismic data between two stratigraphics to be regarded as relative age cube, which is suit for more complete sedimentary strata environment, parallel or sub-normal deposition pattern.

For continental transpressional basins, erosion often occurs at the top stratigraphic, overlap occurs at the bottom and over thrust also occurs. For these three slices, there are more serious diachronous which are not used to simulate real stratigraphic sedimentary phases. Based on the above understanding, three-dimensional Wheeler slicing techniques [20] [21] in data-driven ways was proposed to simulate complex deposition, and then the Wheeler transformation was made to slice the data constrained by the minimal seismic isochronal unit. 


\subsubsection{Seismic Geomorphology}

In wheeler domain, water body changing characteristics can be more easily identified in vertical to interprete the maximum flooding surface and the initial flooding surface and ultimately determine the location of the various systems tracts (high stand system track, lake transgression track and low stand system track). In the plane, each system can be identified through isochronal stratigraphic slice. The lithology and distribution of sedimentary body can be predicted in time and space on the basis of calibration with Wheeler domain to predict sedimentary environment and research space evolution of sedimentary bodies.

\subsection{Study Methods and Thoughts}

On the basis of the correct identification of the isochronal surface (seismic and geological), the minimum isochronal unit can be identified controlled by isochronal framework to trace chronostratigraphy and build deposition rhythm body to achieve the formation slices. According to reservoir parameters of different sediments (rock size, thickness, porosity) in the study area, the rock physics forward was done to establish different types of seismic response characteristics of deposition. The sedimentary facies and their evolution were analyzed by using use of seismic attributes, seismic facies analysis, frequency (horizontal), time-frequency analysis (vertical) and isochronal stratigraphic technique within minimum unit (Figure 2).

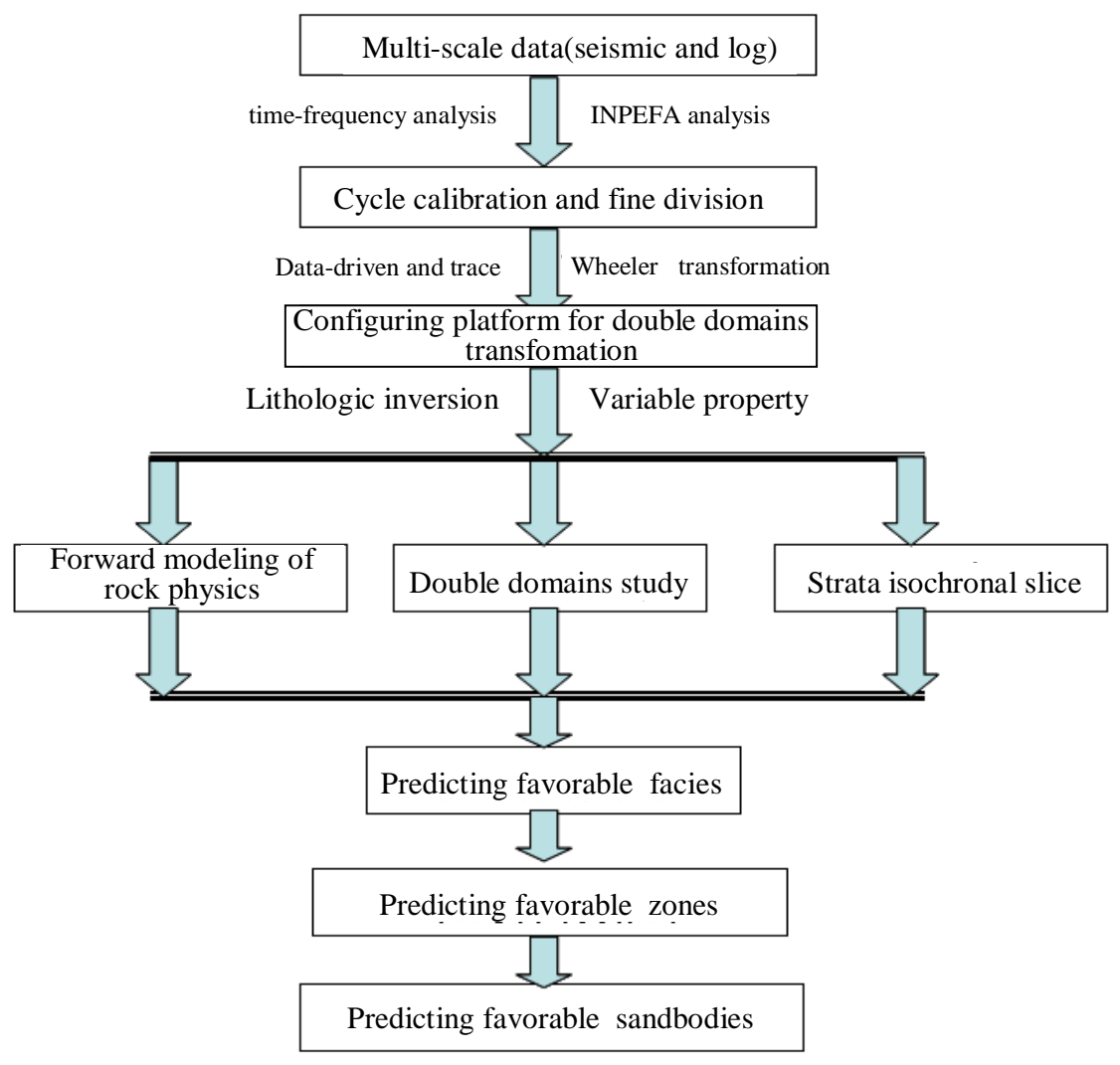

Figure 2. The flow chart of seismic geomorphology study. 


\section{Application of Seismic Sedimentology to the Central of Juggar Basin}

The main target zone in Central Juggar Basin is Jurassic Sangonghe Formation. In the study starting from the stratigraphic sequence, the fine stratigraphic framework was established for the study area to identify isochronal interface and build minimum research unit through combination of seismic data and logging data. The relationship between rock lithology and seismic physical properties could be determined by studying rock lithologic, logging and seismic response characteristics. According to the study area deposition model for the study area the stratigraphic slice model was established to make interpretation in both Wheeler domain and time domain to predict reservoirs and identify favorable sands.

\subsection{Jurassic Sequence Division}

According to the deposition rhythm of strata, using logging and seismic cycle analysis, combining with major target zones in Juggar transpressional superimposed basin, applying sedimentary geology identification, analyzing log spectral properties trend and seismic sequence identification marks, the Jurassic stratigraphic sequence is divided as follows: early Jurassic sequence group $\left(\mathrm{Ss}_{1} \mathrm{H}_{1}\right.$ ) is between the regional unconformities of $\mathrm{SBJ}_{1} \mathrm{~b}_{3}$ and $\mathrm{SBJ}_{2} \mathrm{t}$. It is divided into six sequences. Among them, Badaowan Formation is divided into two sequences which are namely $\mathrm{SqJ}_{1} \mathrm{~b}_{2-3}$ sequence and $S q J_{1} \mathrm{~b}_{1}$ sequence. The Sangonghe Formation is divided into two sequences which are $\mathrm{SqJ}_{1} \mathrm{~s}_{3}$ sequence and $\mathrm{SqJ}_{1} \mathrm{~s}_{2}-\mathrm{s}_{1}$ sequence. The Xishanyao Formation is divided into two sequence which are $\mathrm{SqJ}_{2} \mathrm{x}_{2}$ sequence and $\mathrm{SqJ}_{2} \mathrm{x}_{1}$ sequence (Figure 3 ). Their characteristics are as follows: 1 ) The sequence unit is obviously asymmetry, in which Changji deposition was thicker the stratigraphic was thinner and thinner from central beam to Chemo Uplift and piedmont zone; 2) the top and bottom of each sequence were obvious unconformities in the basin margin and its paleo-uplift. Especially in the late Xishanyao sedimentary period, the Chemo Uplift was truncated obvious and the stratigraphics were lack obviously, which indicats that the central paleo-uplift (Chemo and Luliang palaeo-uplift) controlled the sequence composition, while most of the integration of depression existed in Changji Sag, or at the bottom of the interface there was characterized by baselap.

\subsection{The Reservoir Seismic Lithology Study}

This study not only used rock physics test data, but also used log intersection analysis to make additional analysis. It analyzed the relationship between lithology and physical properties (porosity and permeability) and seismic attributes to find out the sensitive parameters of the seismic study area.

\subsubsection{Rock Physical Analysis}

Through all wells curves normalization in the study area it is considered that it is feasible to use impedance values to distinguish sand from shale. But there is still a multi-solution in distinguishing muddy silt from sandy mudstone (Figure 4). It is more complex of the corresponding relationships between lithology and amplitude through 


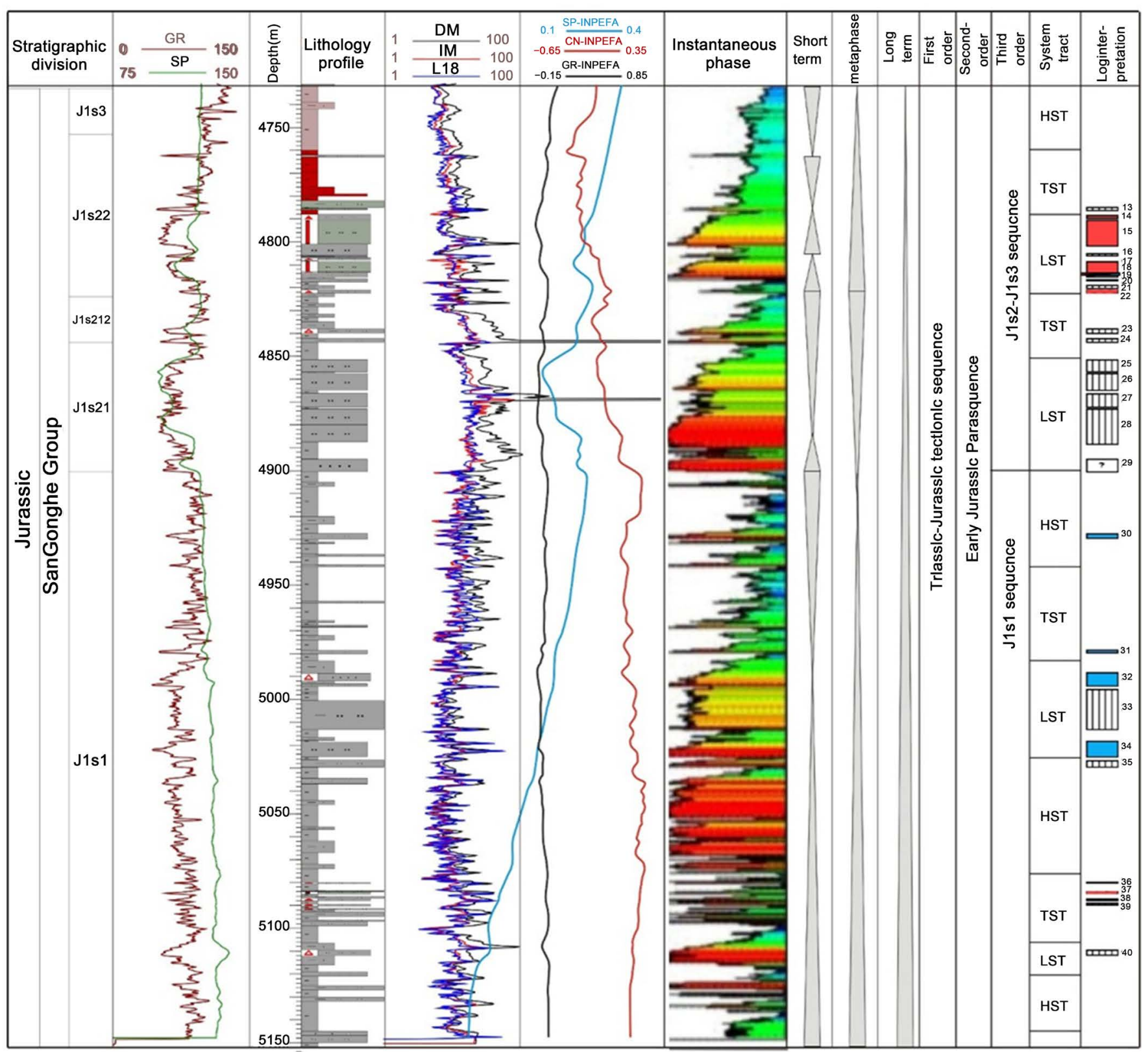

Figure 3. The sedimentary facies sequence division diagram for sha1 well.

plotting lithologic across seismic attributes. But in general the absolute value or RMS amplitude of sandstone is higher than that of shale which could be used to .roughly divide the lithology, but there are still some multiple solutions. This complex elation ship was resulted from more continental basins material source, a thin layer and lithologic complexity.

Rock geophysical testing and the statistics of favorable reservoir thickness, lithology, physical properties and speed show that the thickness of sand has a certain positive correlation with rock velocity, which average velocity of sand is greater with the greater thickness, different rock had different velocity. In general, conglomerates velocity is 


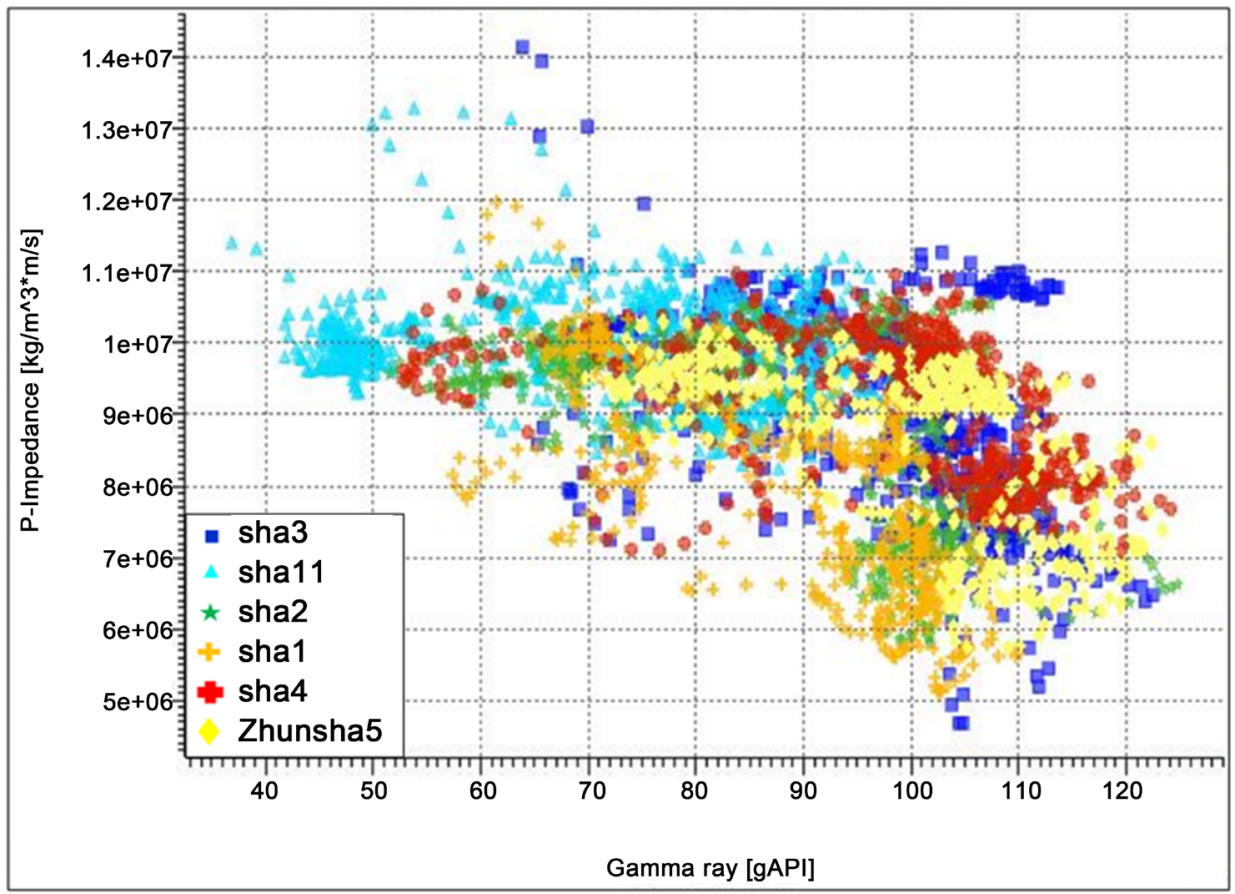

Figure 4. GR-impedance crossplot.

largest, sandstones velocity is second, the mudstone velocity was lowest; rock porosity has a certain negative correlation with the rock average velocity. The porosity is higher and the velocity is lower. In addition, pre-migration parameter $\lambda / \mathrm{G}$ and $\lambda \rho$ are more sensitive for identifying fluid (Figure 5).

\subsubsection{The Division of Minimum Isochronal Unit}

The scale of various measurements is different the scale of logging is higher than that of seismic. In order to compare in horizontal, the smallest unit scale depends on the accuracy of seismic identification. The stratigraphics of $\mathrm{J}_{2} \mathrm{x}, \mathrm{J}_{1} \mathrm{~s}_{1}, \mathrm{~J}_{1} \mathrm{~s}_{2}{ }^{1}, \mathrm{~J}_{1} \mathrm{~s}_{2}{ }^{2}$ are relatively thinner with about 30 - 50 meters, which was divided into two minimum study units through the log and seismic joint calibration combining with the cyclic [22]. The stratigraphyic of $\mathrm{J}_{1} \mathrm{~s}_{3}$ is thick with nearly 100 meters which was divided into seven minimum research units. It is noteworthy that the thickness of each study unit is not equal with 8 - 30 meters, but their specific thickness was determined according to cyclicity, as each minimum research unit was determined as much as possible within one cycle (Figure 6).

\subsection{Seismic Geomorphology Study}

\subsubsection{The Configuration of Isochronal Slice}

In the central of Juggar Basin due to gentler slopes of stratigraphic, far away from the source, the weak hydrodynamic conditions, low seismic resolution and other factors, $\mathrm{J}_{1} \mathrm{~s}_{2}{ }^{1}$ strata appear in the seismic profile, retro gradation of the different sand bodies were reflected with one phase event in seismic section within $\mathrm{J}_{1} \mathrm{~s}_{2}{ }^{1}$. The amplitude is enhanced when variable sand bodies were overlapped, the reflected event is 


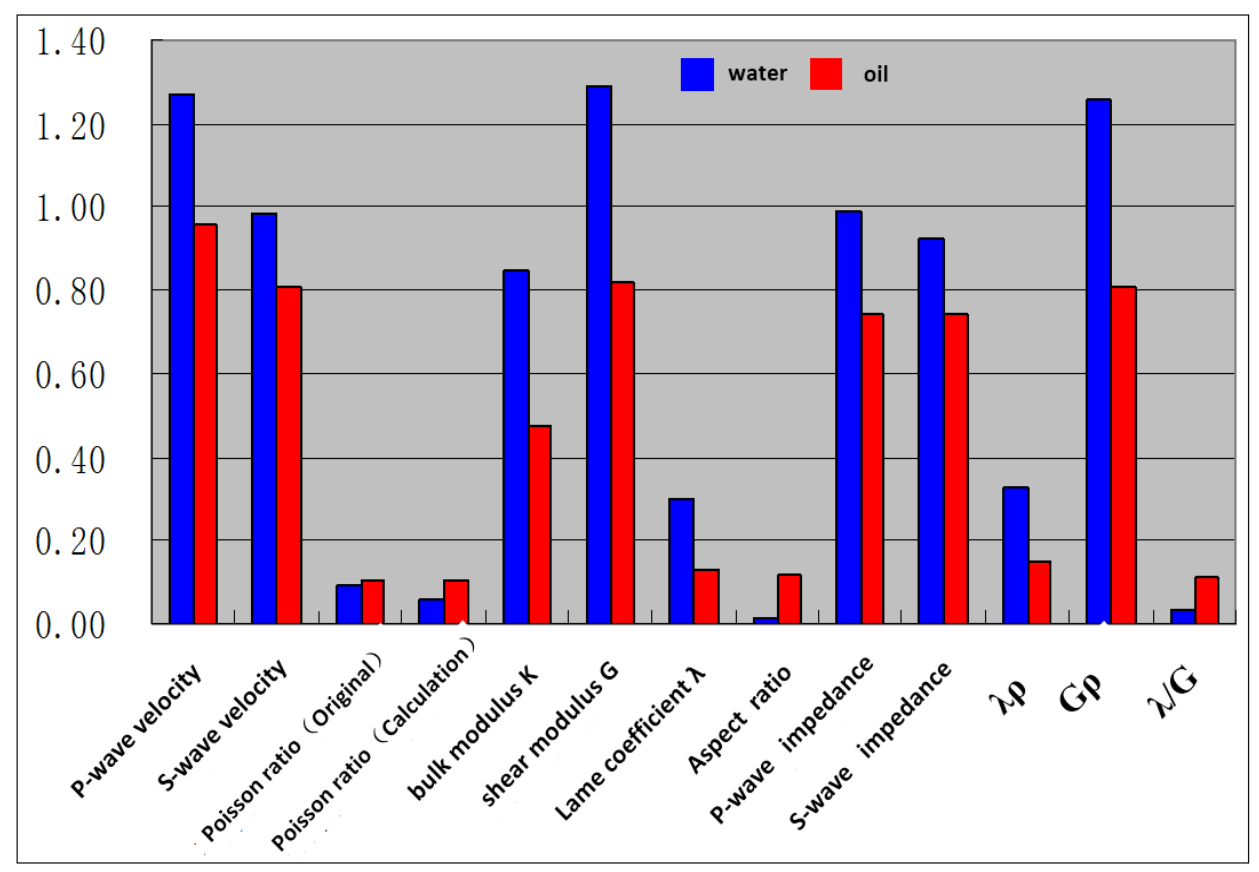

Figure 5. The histogram of sensitive seismic properties in Zhengshachun area.

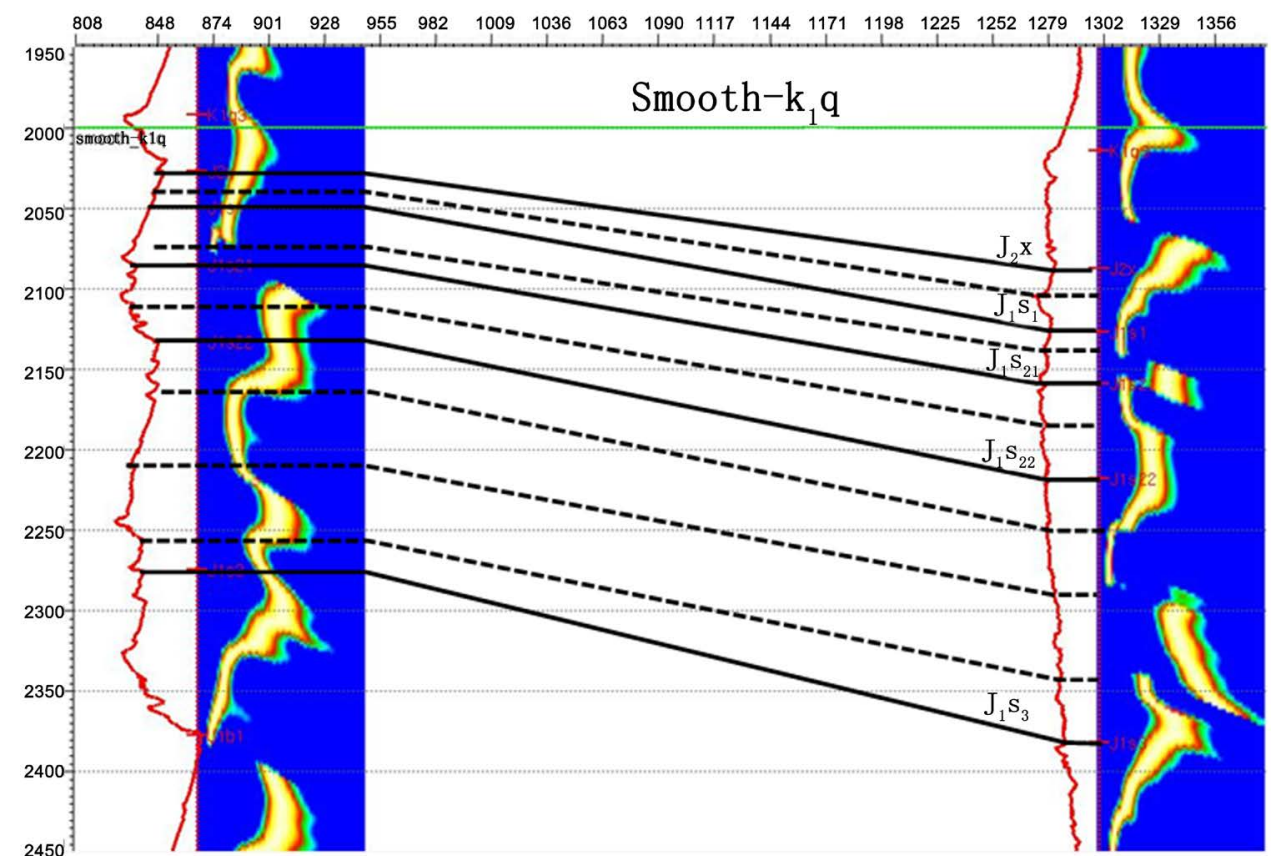

Figure 6. The division of minimum.

isochronal unit across wells attributes in Wheeler domain in Zhengshachun Area distorted and partial complex wave phenomena can be found. In order to distinguish different sand body distribution, the deposition mode was simulated finely according to seismic dip, azimuth using data-driven automatic tracking, and then Wheeler transformation (Figure 7) was made to establish isochronal slice within minimum unit. 


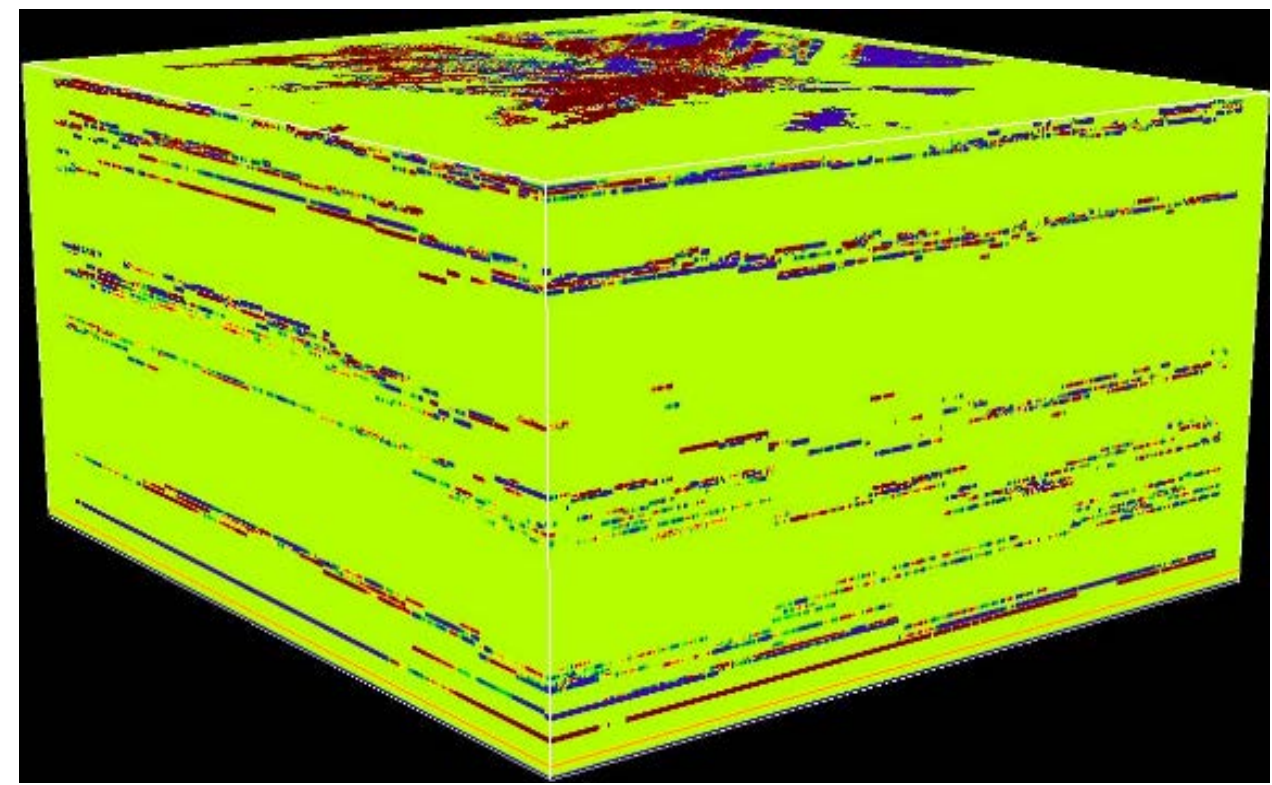

Figure 7. The stereogram of seismic attributes in Wheeler domain in Zhengshachun Area.

\subsubsection{Attribute Analysis in Double Domains}

Because each layer had not been compared and traced during seismic attributes extraction process in time domain, the attribute is extracted from isochronal slice parallel to top and bottom interface, which can only be reflected seismic attributes features within a certain range and there is still appeared to be not a isochronal interface to lead to seismic attributes cannot be a true reflection of sedimentary characteristics. In Wheeler domain seismic attributes can be extracted along any small surface to achieve the extraction and analysis of seismic attributes in isochronal interface and reflect seismic response characteristics of sedimentary bodies developing at the same period.

It can be found from Figure 8 that impedance has good relationship with amplitude, which is strong impedance corresponding to strong amplitude and its source material is mainly speculated from the northeast, water power is relatively weak in north west of the material source, so sand distribution is relatively small in the study area. In the southern study area, the formations are thin which are speculated to be mainly impacted by Chemo Uplift. The distribution of sand bodies was described using amplitude and impedance properties. The drilling shows that the southern sand body is a relatively thin, but have good reservoir physical properties, while northern sand body is relatively thick, but the physical properties are rather poor.

\subsubsection{Reservoir Evolution Analysis}

The $\mathrm{J}_{1} \mathrm{~s}_{1}$ developed mainly mudstone to reflect the shallow lacustrine depositional environment by analyzing Jurassic sedimentary cycles Sangonghe and researching the minimum unit (Figure 6, Figure 9, Figure 10), among which $\mathrm{J}_{1} \mathrm{~s}_{1}{ }^{1}$ was highstand system track with aggradation and reciprocal sedimentation in a smaller range. The lower formation was a lake transgrasive system track with progradation and reciprocal sedi mentation in a larger range. There developed sand bodies in regional study area. The 

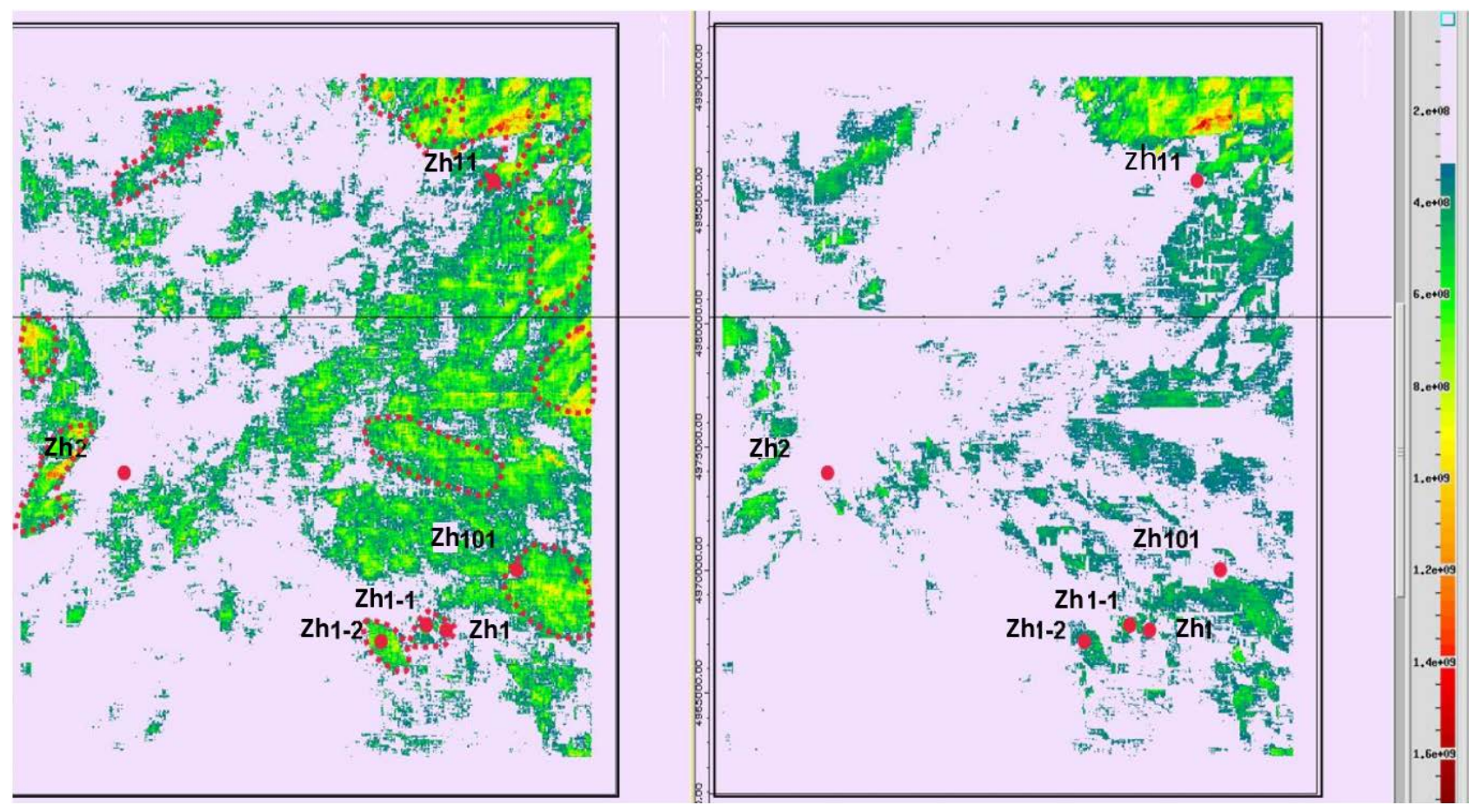

Figure 8. The $\mathrm{J}_{1} \mathrm{~s}_{2}{ }^{1-1}$ impedance in Wheeler (left) and amplitude energy (right).

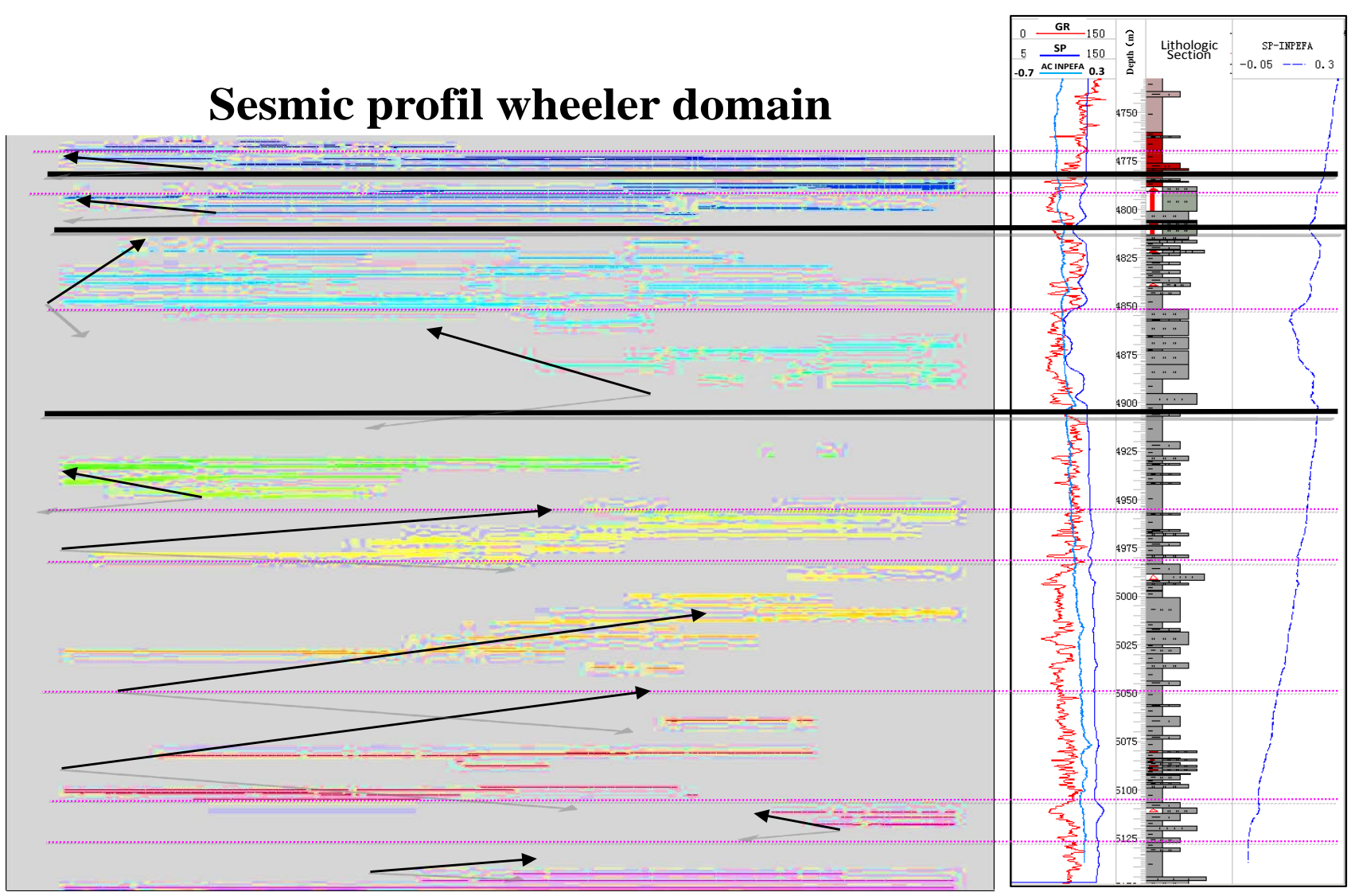

Figure 9. The section of sedimentary evolution (noting: the blank shows sedimentary breaking). 


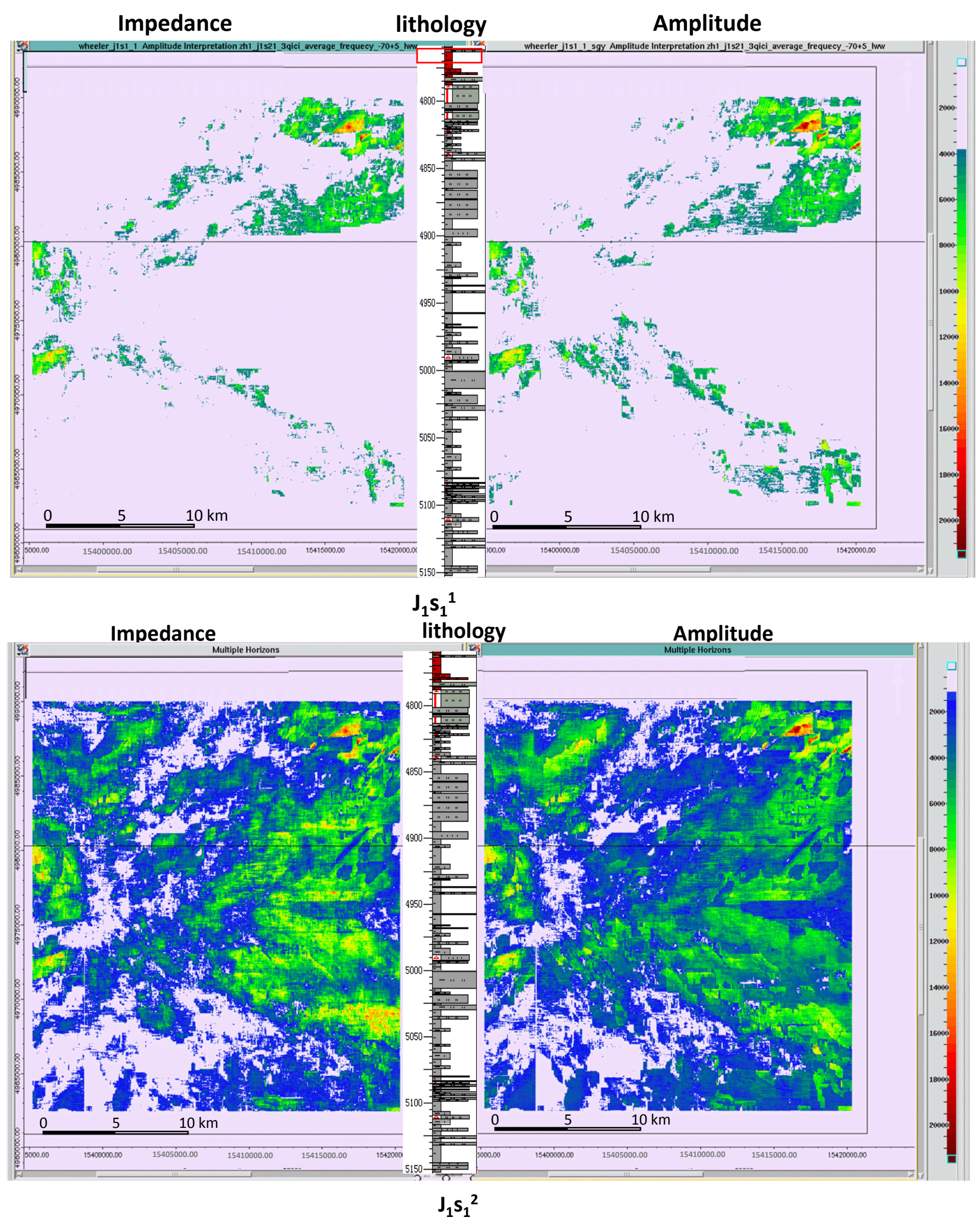



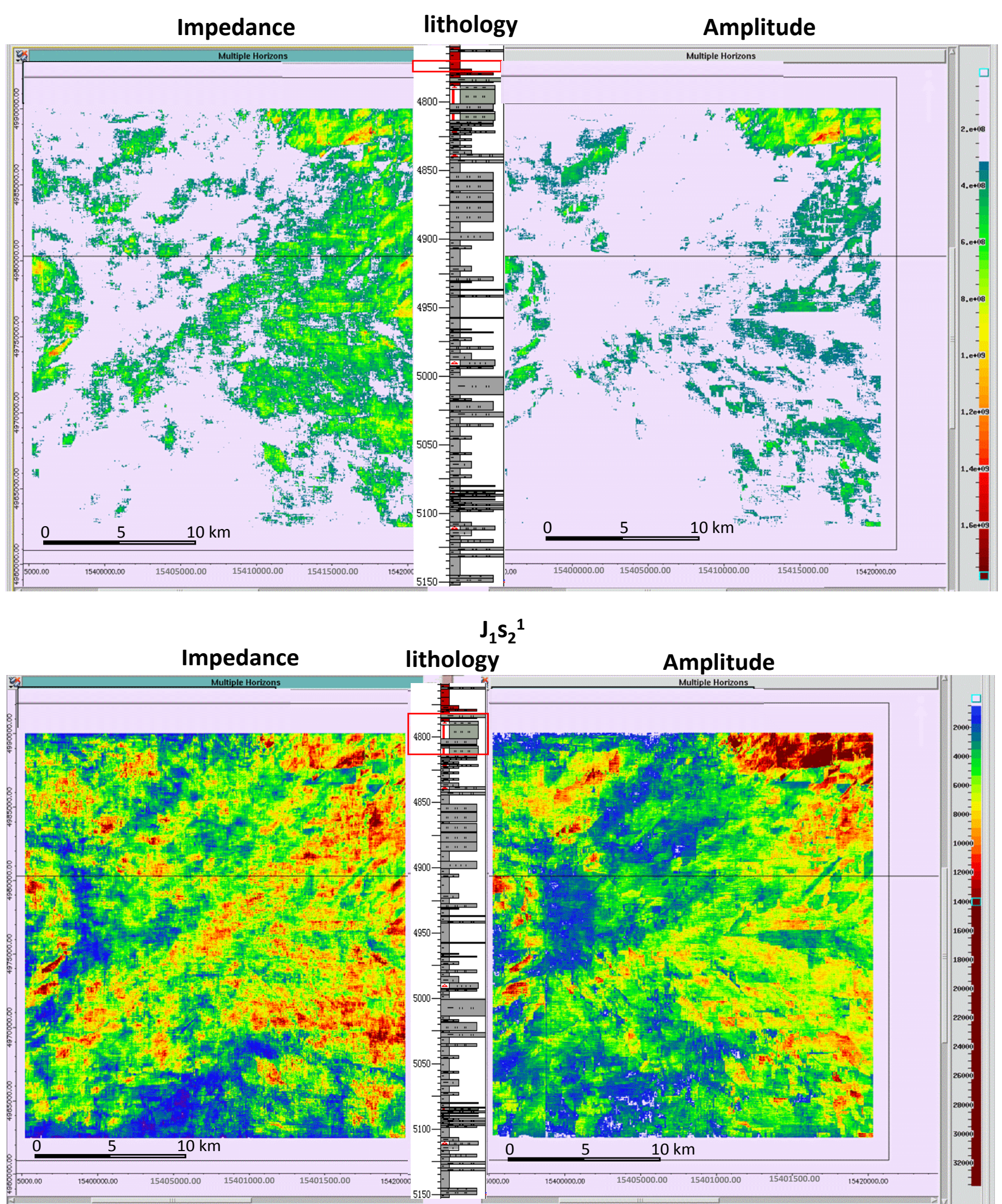

lithology

Amplitude

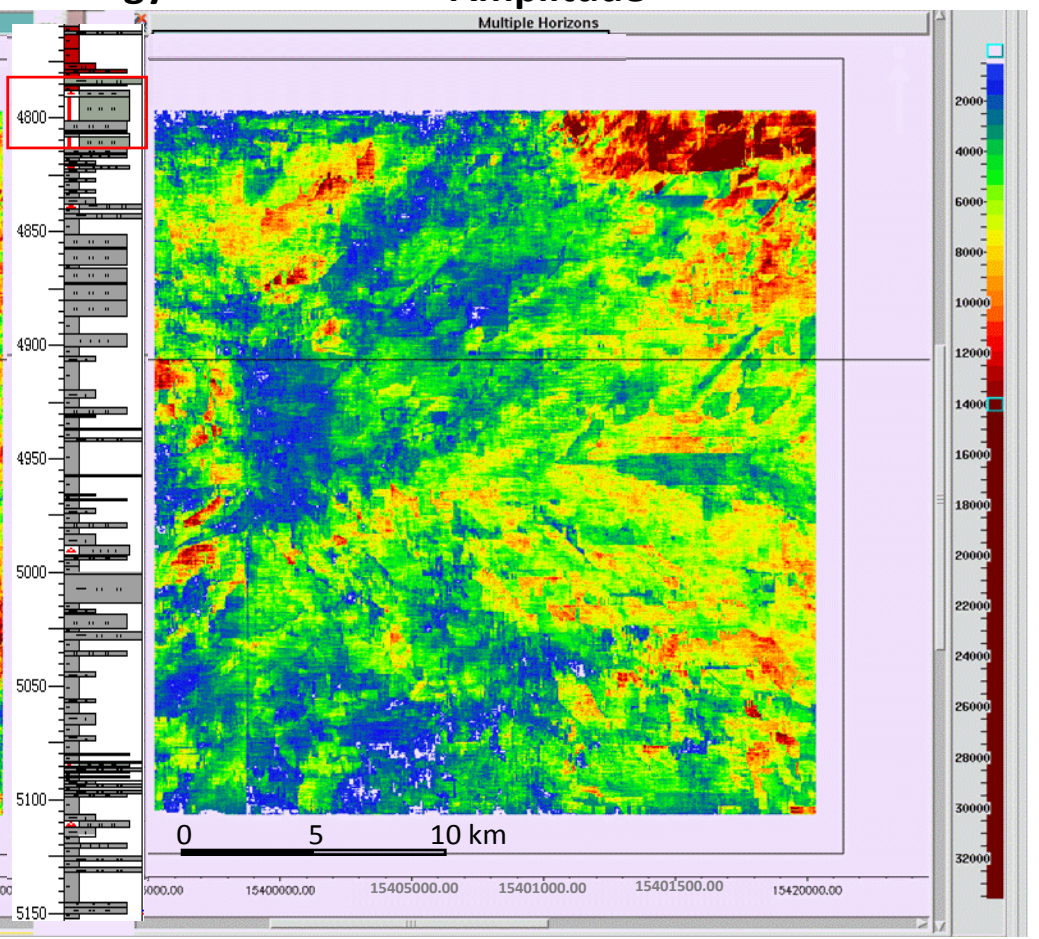

$\mathrm{J}_{1} \mathrm{~s}_{2}{ }^{2}$ 

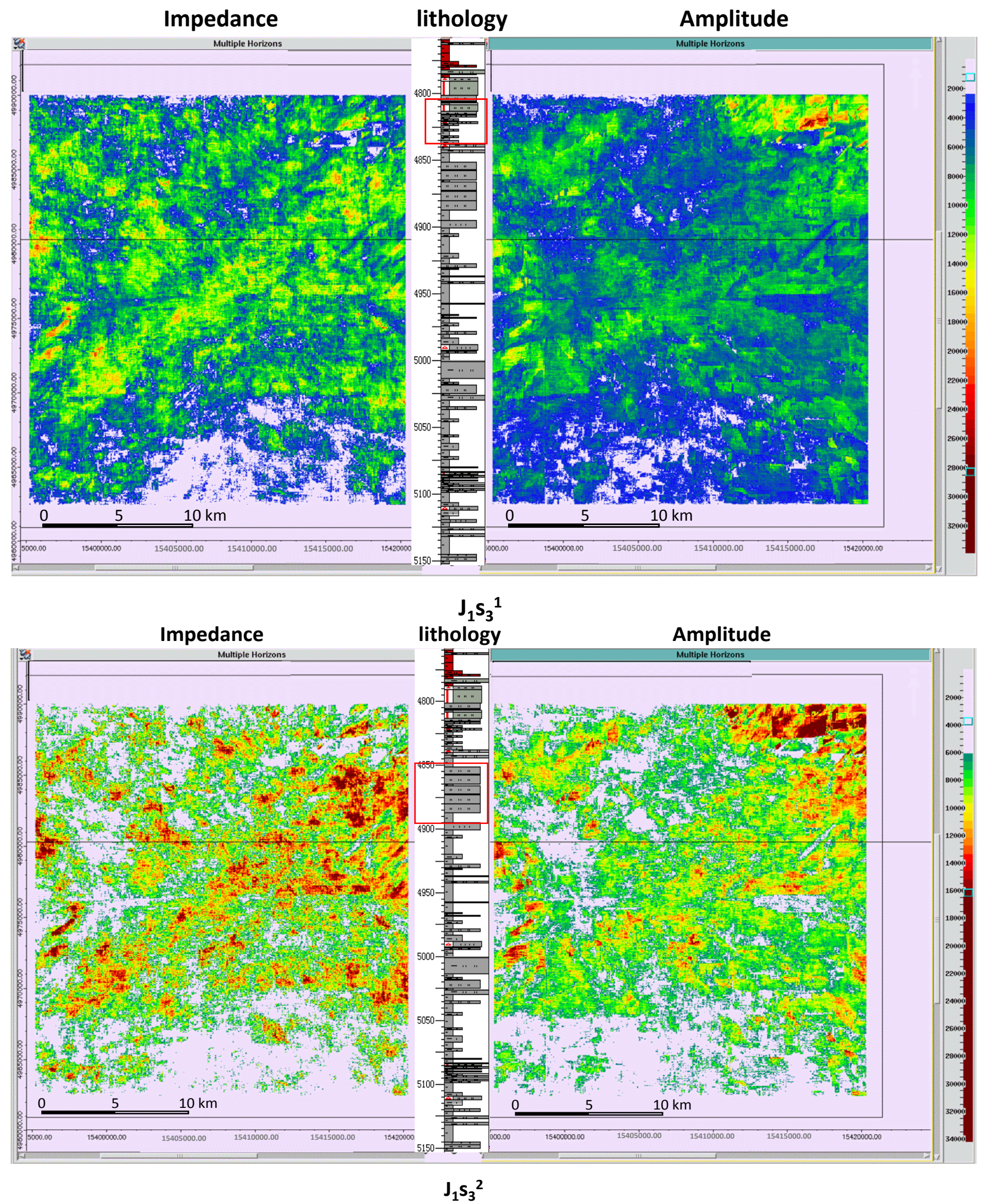


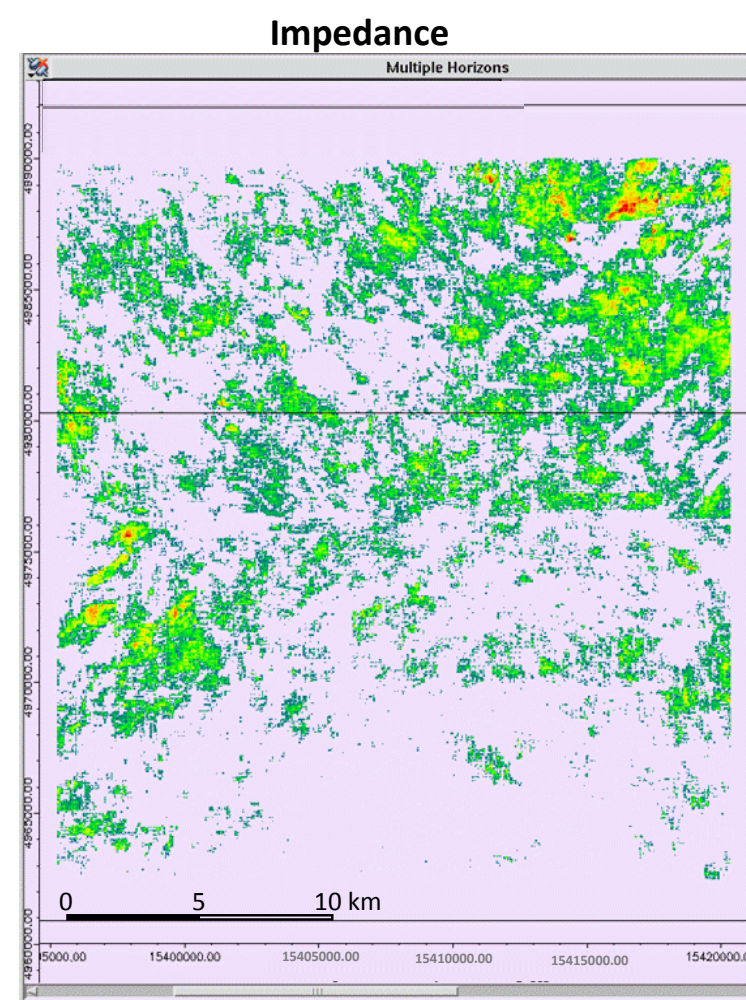

\section{lithology}

Amplitude

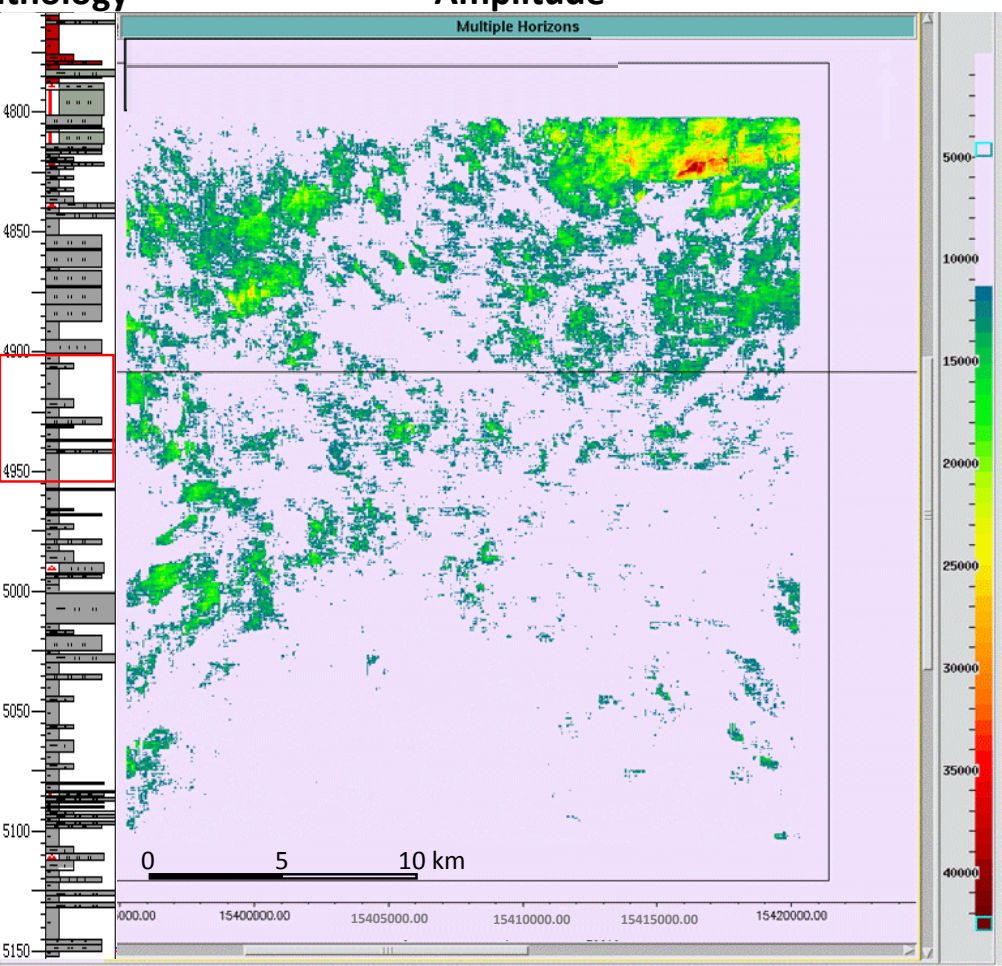

Impedance

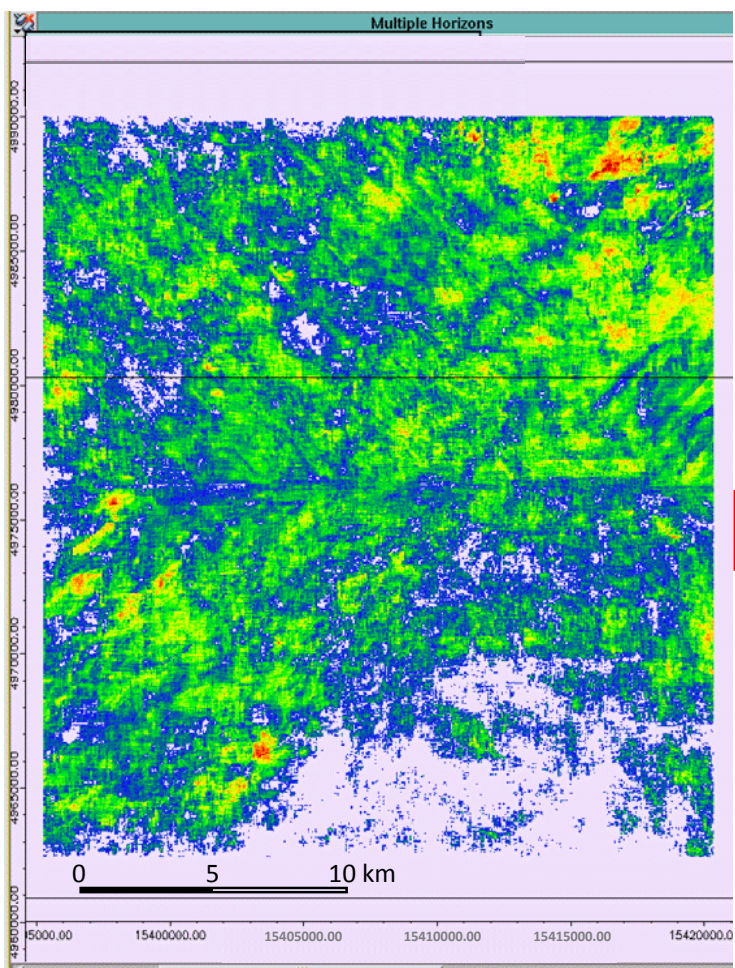

$\mathrm{J}_{1} \mathrm{~S}_{3}{ }^{3}$

lithology Amplitude

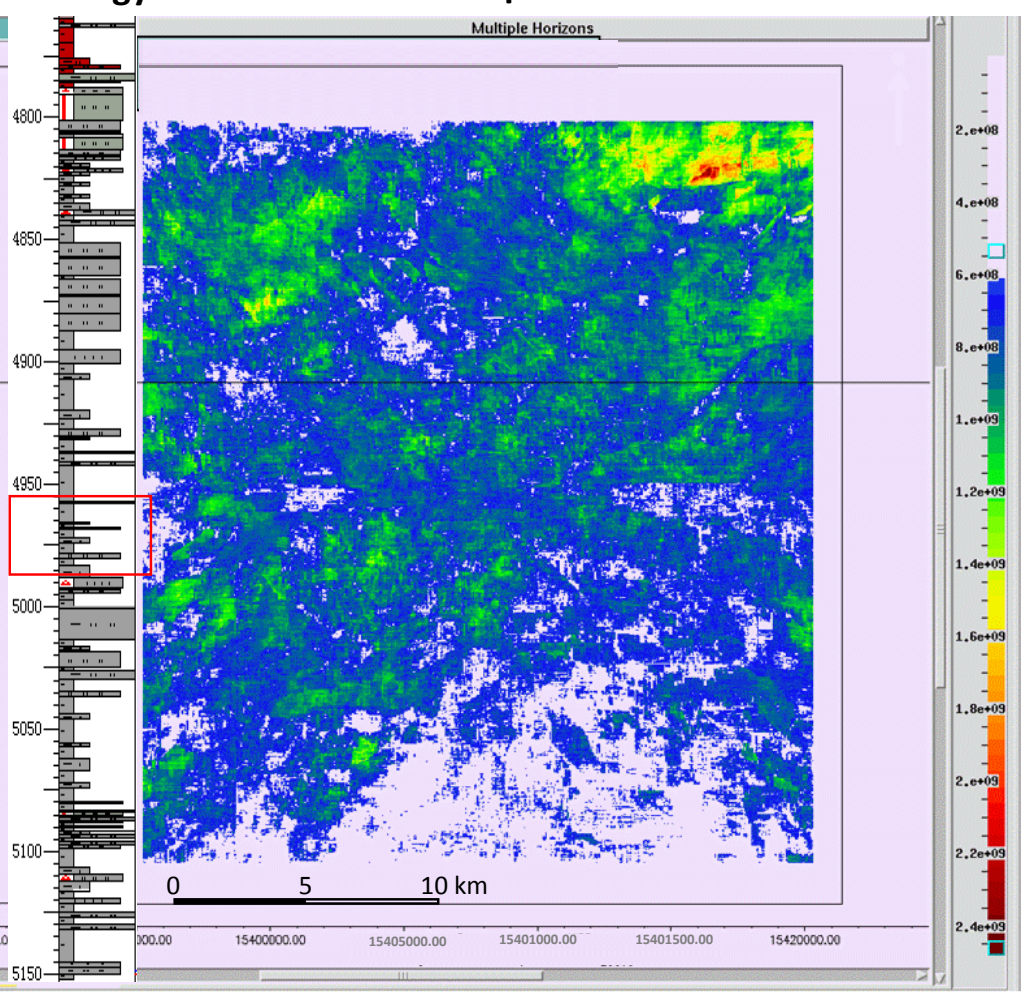

$\mathrm{J}_{1} \mathrm{~s}_{3}{ }^{4}$ 

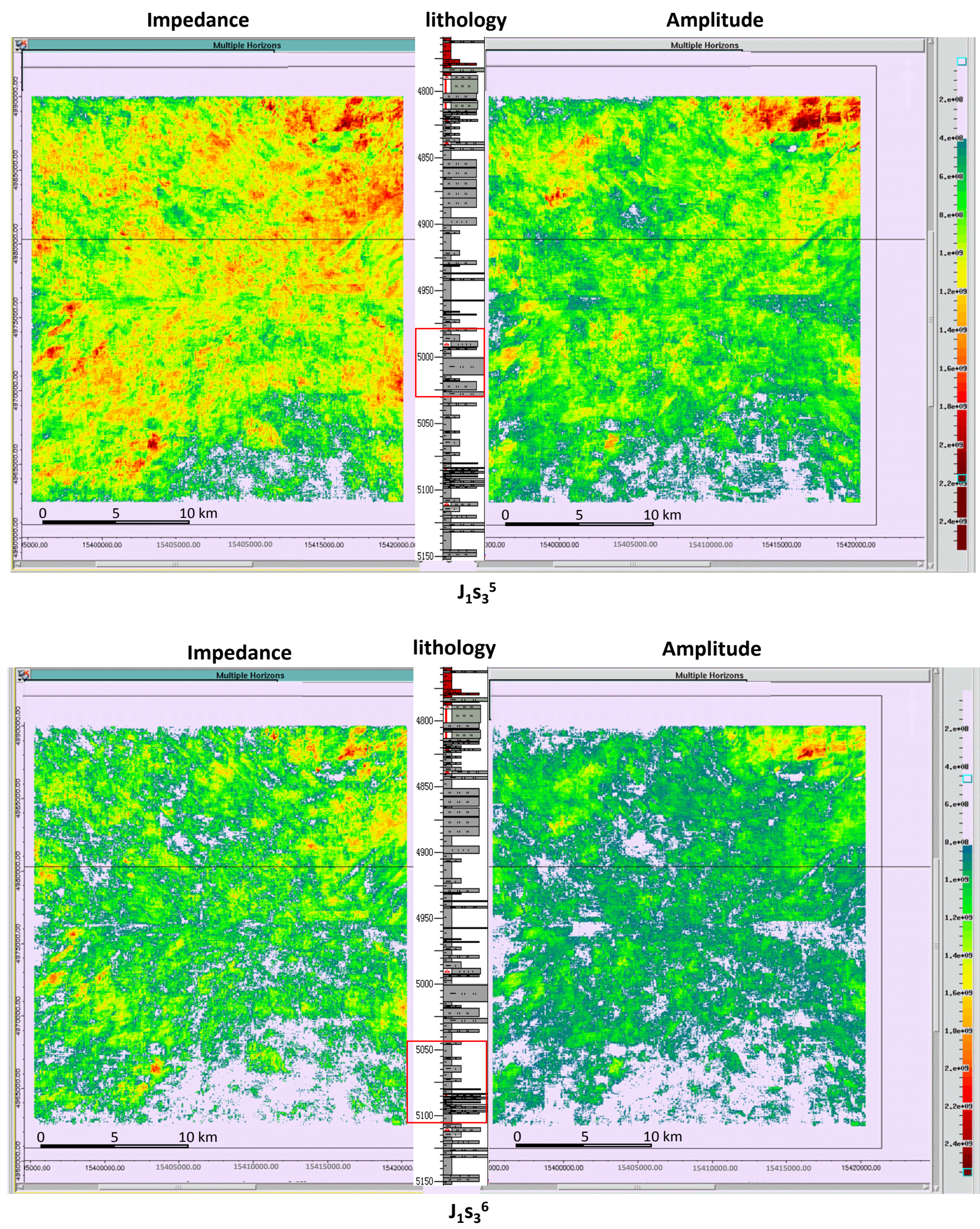


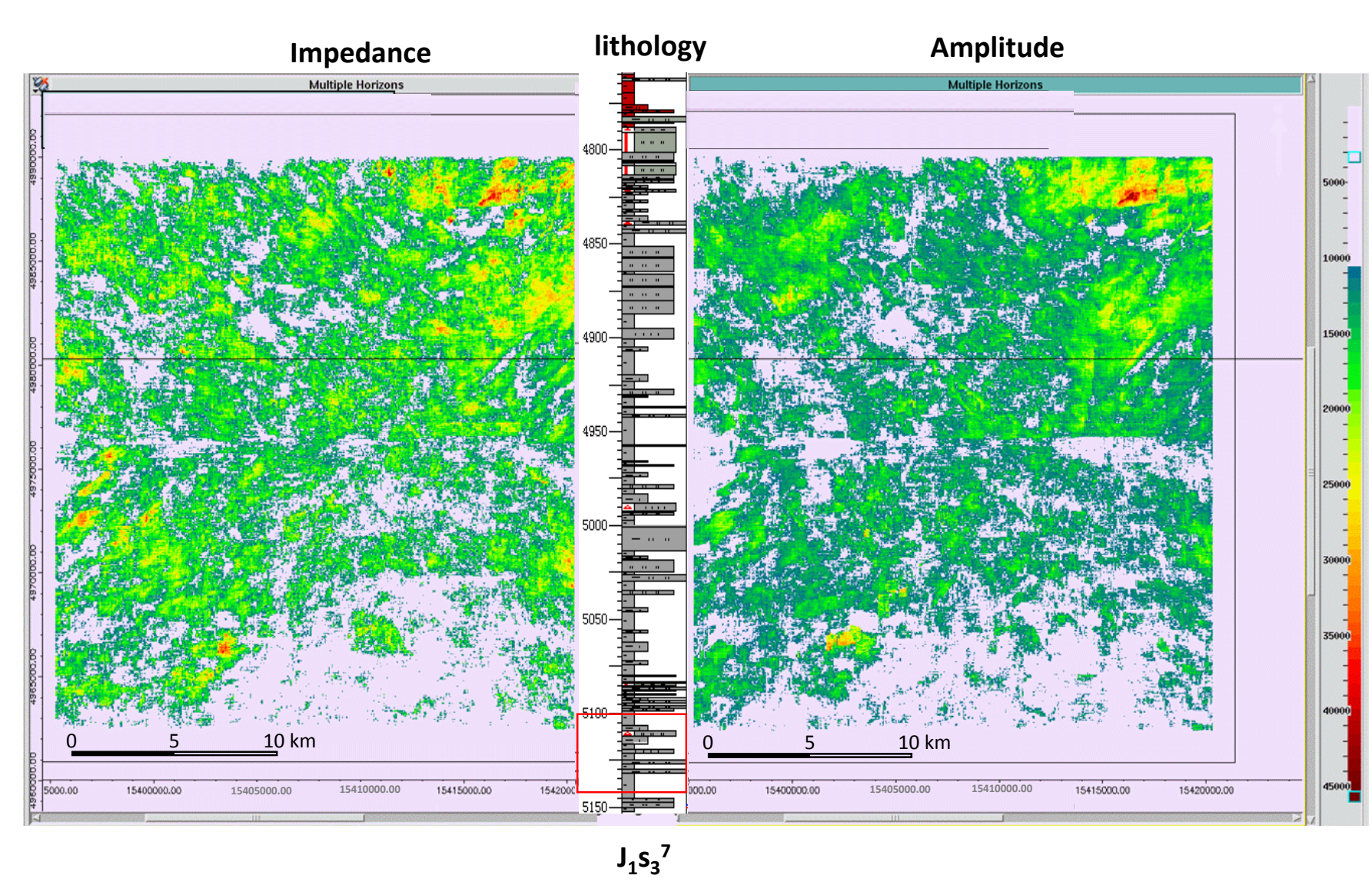

Figure 10. The maps of amplitude and impedance of $\mathrm{J}_{1} \mathrm{~s}_{2}{ }^{1}$ sequence cycle in Zhengshacun Area (noting: the blank shows the sedimentary breaking, the high impedance shows in red and yellow, the low impedance shows in blue. The rectangular shows the location of slice).

$\mathrm{J}_{1} \mathrm{~s}_{2}$ developed mainly mudstone to reflect the meandering delta sedimentary environment, among which $\mathrm{J}_{1} \mathrm{~s}_{2}{ }^{1}$ is highstand system track with aggradation and cycle sedimentation in a smaller range developing mainly in the east study area. The $\mathrm{J}_{1} \mathrm{~s}_{2}{ }^{2}$ was a lake transgrasive system track with retrogradation and cycle sedimentation in a larger range. There developed sand bodies in east study area and small sand bodies developed in west area.

$\mathrm{J}_{1} \mathrm{~s}_{3}$ developed mainly sandstone to reflect braided stream deltas sedimentary environment, which is divided into seven layer and each layer is not described in detail for paper limitation.

\subsection{Reservoir Predict}

Seismic geomorphology analysis not only helps to predict microfacies, but also controls the prediction of favorable sand bodies. However, plane properties can be extracted from relative to be imaged. But the plane properties in Wheeler domain can only be used to characterize the shape and distribution of geochronology cube without calculating thickness. Therefore, it is required to establish a same properties cube (multi-attribute volumes) in double domains (conventional time domain and Wheeler domain) to display, analyze and interpret interactively in order to make the extracted 
seismic properties reflecting not only shape and distribution of the sand bodies but their thickness.

After the horizon in Wheeler domain was flattened to remove the structure background, the sedimentary was more prominent to show sand body. The boundary of each period sand body developing in Shawodi-Moxizhuang and Zhengshachun area has been determined after a comprehensive prediction controlled by phases to predict the thickness and make a map. 57 sand bodies at $\mathrm{J}_{1} \mathrm{~s}_{2}{ }^{1}$ formation in the central of Juggar Basin has been described using the method to predict favorable area $914 \mathrm{~km}^{2}$.

\section{Conclusions}

Two conclusions were made through application of seismic sedimentology to the central Junggar Basin continental transpressional clastic exploration:

1) Seismic sedimentology depends on sequence stratigraphic framework to ensure isochronous stratigraphic correlation through layer fine contrast and division. The isochronal slice takes full advantage of such seismic lateral resolution features to identify the thin layer. The favorable sand bodies can be predicted effectively in Wheeler domain through studying seismic attributes, which is a powerful tool for subtle hydrocarbon reservoirs. It is a worthy improvement and promotion of new technologies which are improved basing on such seismic sedimentology, and conformed by drilling that the reservoirs prediction was accuracy.

2) There are still many limitations resulted from the application of seismic sedimentology of core technology (900 phase shift, formation slices) to a complex study of the hidden traps developing in Junggar Basin. The technique should be used with constrain according to actual situation. In addition, currently seismic sedimentology has not formed a complete theoretical system, and a lot of research should be carried out. So the study of seismic sedimentology is both theoretical forward-looking and challenging, but also has practical exploration needs.

\section{References}

[1] Zeng, H.L., Backus, M.M., Barrow, K.T., et al. (1998) Stratal Slicing, Part I: Realistic 3-D Seismic Model. Geophysics, 63, 502-513. http://dx.doi.org/10.1190/1.1444351

[2] Zeng, H.L., Backus, M.M., Henry, S.C., Riola, J.P. (1998) Stratal Slicing, Part II: Realistic Seismic. Geophysics, 63, 514-522. http://dx.doi.org/10.1190/1.1444352

[3] Zeng, H.L. and Hentz, T.F. (2004) High-Frequency Stratigraphy from Seismic Sedimentolgoy: Applied to Miocene, Vermilion Block 50, Tiger Shoal Area, Offshore Louisiana. AAPG Bulletin, 88, 153-174. http://dx.doi.org/10.1306/10060303018

[4] Zeng, H.L. (2011) Seismic Sedimentology in China: A Review. Acta Sedimentologica Sinica, 29, 417-425.

[5] Zeng, H.L. and Kerans, C. (2003) Seismic Frequency Contal on Carbonate Seismic Stratigraphy: A Case Study of the Kingdom Abo Sequence, West Texas. AAPG Bulletin, 87, 273-293. http://dx.doi.org/10.1306/08270201023

[6] Li, Q.Z. and Zhang, J. (2006) The Lithologic Hydrocarbon Exploration-The Study Methods for Channel Sandy Reservoirs. China Ocean University Press, Qingdao, 130. 
[7] Dong, C.M. and Zhang, X.G. (2006) Discussion on Seismic Sedimentology. Oil Geophysical Prospecting, 41, 405-409.

[8] Liu, B.G. and Liu, L.H. (2008) Application of Applied Seismic Sedimentology in Sedimentary Facies Analysis. Geophysical Prospecting for Petroleum, 47, 266-271.

[9] Lu, Y.C., Du, X.B., et al. (2008) Main Methods System of Fine Petroleum ExplorationSeismic Sedimentology. Petroleum Geology \& Experiment, 30, 1-5.

[10] Yang, X.F., Zhang, X.W. et al. (2008) New Advances in Seismic Geomorphology. Special Oil \& Gas Reservoirs, 15, 1-5.

[11] Li, B., Song, Y., et al. (2009) Discussion and Application of Seismic Sedimentology. Acta Geologica Sinica, 83, 820-826.

[12] Lin, C.X. and Zhang, X.G. (2006) The Discussion of Seismic Sedimentology. Advances in Earth Science, 21, 1140-1144.

[13] Wang, Z.H., Jiang, N.C., et al. (2008) Conception, Method and Application of the Seismic Sedimentology. Journal of Chongqing University of Science and Technology (Science \& Technology Edition), 10, 25-27.

[14] Dong, C.M., et al. (2006) Conception, Method and Technology of the Seismic Sedimentology. Acta Sedimentologica Sinica, 24, 698-704.

[15] Wang, Z.H. (2008) The Concept and Methods and Application of Seismic Sedimentology. Inner Mongolia Petrochemical Industry, 34, 23-25.

[16] Li, X.P., Zeng, H.L., et al. (2008) Mapping Deltaic Depositional Systems Using Seismic Sedimentology. Journal of Chengdu University of Technology (Science \& Technology Edition), 35, 625-629.

[17] Qian, R.J. (2007) Analysis of Questions on Seismic Slice Interpretation. Progress in Geophysics, 42, 482-487.

[18] Li, Q.Z. (2008) Discussion on Seismic Exploration of Litgologic Reservoirs (I). Lithologic Reservoirs, 20, 1-6.

[19] Wang, Y.G., Han, W.G. and Liu, H.J. (2008) Review of Match Methods for Multi-Scale Seismic Data. Progress in Geophysics, 43, 333-339.

[20] Luo, H.M., Xing, L., et al. (2009) Geological Process Controlled Interpretation Based on 3D Wheeler Diagram Generation. Foreign Oil Field Engineering, 25, 1-2.

[21] Startk, T.J. (2004) Relative Geologic Time (Age) Volumes-Relating Every Seismic Sample to a Geologically Reasonable Horizon. The Leading Edge, 23, 928-932. http://dx.doi.org/10.1190/1.1803505

[22] Liu, Z.F., et al. (2004) Geophysical Study of Sedimentary Cycles. Petroleum Geology \& Experiment, 26, 258-262. 
Submit or recommend next manuscript to SCIRP and we will provide best service for you:

Accepting pre-submission inquiries through Email, Facebook, LinkedIn, Twitter, etc. A wide selection of journals (inclusive of 9 subjects, more than 200 journals)

Providing 24-hour high-quality service

User-friendly online submission system

Fair and swift peer-review system

Efficient typesetting and proofreading procedure

Display of the result of downloads and visits, as well as the number of cited articles

Maximum dissemination of your research work

Submit your manuscript at: http://papersubmission.scirp.org/

Or contact ojogas@scirp.org 